\title{
EXPERIMENTAL INVESTIGATION ON HALLOYSITE NANO TUBES \& CLAY AN INFILLED COMPOSITE STEEL TUBE
}

\author{
Vindhya C.R ${ }^{1}$, Hafeez Khan ${ }^{2}$, N.S Kumar ${ }^{3}$ \\ ${ }^{I}$ Master of Technology (Structural Engineering) student, Department of Civil Engineering, GCE Ramanagaram, \\ Karnataka India \\ ${ }^{2}$ Master of Technology (Structural Engineering) student, Department of Civil Engineering, GCE Ramanagaram, \\ Karnataka India \\ ${ }^{3}$ Professor \& Director (R\&D-Civil Engg) GCE Ramanagaram, Karnataka India
}

\begin{abstract}
This research aims at Comparative experimental behavior of Halloysite Nano Tubes\& Clay as an in -fill to Composite Steel tubes. Both materials are of Nano category and one is in the tubular form and the other amorphous. Naturally formed in the Earth over millions of years, Halloysite Nano Clay are unique and versatile Nano materials that composed of aluminum, silicon, hydrogen and oxygen and are mined from natural deposits in countries like China, New Zealand, America, Brazil, and France. The effects of the diameter, length of steel tube, grade of concrete \& volume fractions of HNC's to concrete $(0 \%, 0.5 \%, 1 \%, 1.5 \%$, \& $2 \%)$ on the behavior of Halloysite Nano Clay(HNC's) concrete filled steel tube columns under axial compression are presented and compared with that of Nano tubes. Also, Studies are carried out to know the effect of Diameter $(D)$, Change in steel tube length $(l)$, and Strength of infill ( $\left.f_{C K}\right)$ and to determine the ultimate load $\left(P_{u l t}\right) \&$ defection $\left(\triangle_{\text {axial }}\right)$ in HNC's composite steel hollow tubes under monotonic loading and SEM (scanning electron microscope) image are taken during mixing, before testing and after testing and Fracture Analysis will be carried out for the buckled steel tubes using Radiographic Testing.
\end{abstract}

Keywords: Halloysite Nano Clay1, SEM2, Fracture Analysis3.

\section{INTRODUCTION}

Concrete filled steel tubes have been extensively used in the modern Structure mainly due to the combination of the advantage of Steel tube \& Concrete core. The in-fill material inside Steel tubes is required to be of the quality as to increase the ductility, but not the strength of composite columns, many kind of in-fill materials were used to improve ductility of composite columns. Among the various in fill materials, we are using Halloysite Nano Clay (HNC's).

Recent developments in nanoscience and nanotechnology opened fundamental and applied new frontiers in science and materials engineering. Advanced materials are being developed with enhanced chemical and physical properties with unique characteristics. The properties of these materials are determined not only by their composition and chemical bonds, but also by size and morphology. The nanotube (NT) term is recent; the idea of a small tubular structure is not new. In 1930, Linus Pauling (1930) proposed the existence of cylindrical structures formed by minerals in nature.

Naturally formed in the Earth over millions of years, Halloysite Nano Clay are unique and versatile Nano materials that composed of aluminum, silicon, hydrogen and oxygen and are mined from natural deposits in countries like China,
New Zealand, America, Brazil, and France. HNCs are chemically similar to kaolinite and they used in the manufacture of high quality ceramic white-ware. HNTs have high mechanical strength and modulus and these features make it an ideal material preparing for different composites. The formation of halloysite is due to hydrothermal alteration, and it is often found near carbonate. For example, halloysite samples found in Wagon Wheel Gap, Colorado and United are suspected to be the weathering product of rhyolite by downward moving waters. In general the formation of clay minerals is highly favored in tropical and sub-tropical climates due to the immense amounts of water flow. Halloysite has also been found overlaying basaltic rock, showing no gradual changes from rock to mineral formation. Halloysite occurs primarily in recently exposed volcanic-derived soils, but it also forms from primary minerals in tropical soils or preglacially weathered materials. Igneous rocks, especially glassy basaltic rocks are more susceptible to weathering and alteration forming halloysite.

\subsection{Advantages of Halloysite Nanotubes}

- Fine particle size, high surface area and dispersion.

- Implementable in many forms such as powders, creams, gels,

- Superior loading rates to other carriers, Fast adsorption rate

- High aspect ratio, high porosity and non swelling 
- Regeneration ability and increased efficacy

\section{EXPERIMENTAL}

Experiment were carried out on four different specimens with four variations in each specimen, which varies in length $50 \mathrm{~mm}, 75 \mathrm{~mm}, 100 \mathrm{~mm}, 125 \mathrm{~mm}, 150 \mathrm{~mm}$ and $200 \mathrm{~mm}$ with constant diameter $25 \mathrm{~mm}$. And mixed with Cement, Sand \& HNC's $(0.5 \%, 1 \%, 1.5 \%$ and $2 \%)$.

Sample1- 1:2:3 (Cement: HNC: Sand)

Sample2- 1:1.5:3 (Cement: HNC: Sand)

Sample3- 1:2 (Cement: HNC)

Sample4- 2:3 (HNC: Sand)

Sample5- 1:1.5 (Cement: HNC)

Sample6- 1.5:3 (HNC: Sand)

Sample7- Cement

Sample8- HNC's

Sample9- Sand

Sample10- After compression testing

\subsection{Halloysite Nanotubes}

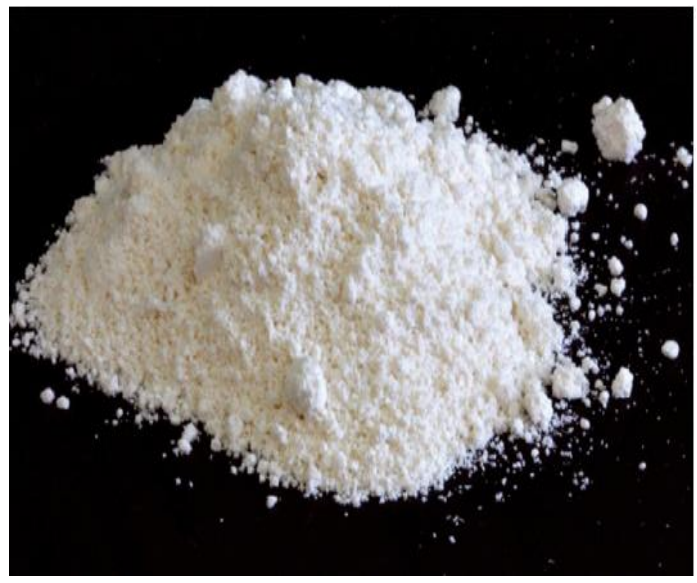

Source: Sigma Aldrich (manufacturer)-New Zealand [1]

Physical and chemical properties (provide by the supplier)

$\checkmark$ Synonyms: Kaolin clay

$\checkmark$ Appearance Form: powder

$\checkmark$ Colour: White to Tan

$\checkmark$ Relative density $2,53 \mathrm{~g} / \mathrm{cm} 3$

$\checkmark$ Formula: H4Al2O9Si2 $\cdot 2 \mathrm{H} 2 \mathrm{O}$

$\checkmark$ Molecular Weight: 294, $19 \mathrm{~g} / \mathrm{mol}$

$\checkmark \quad \mathrm{P}^{\mathrm{H}}$ Value 6.5-6.9

$\checkmark$ Pore volume 1.26-1.34 ml/gm

$\checkmark$ Diameter 30-70nm (nanometers)

$\checkmark$ Length 0.25-4 microns.

\subsection{Characterization}

\subsection{Scanning Electron Microscopy (SEM)}

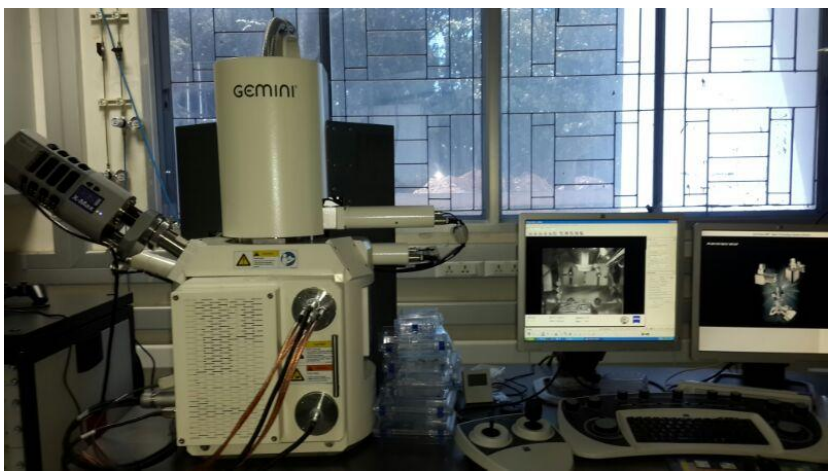

A Scanning electron microscopy [2] imaging was obtained to investigate the microstructures and the fracture surfaces of composites. The samples were mounted on aluminum stubs using carbon tape. The samples were then coated with a thin layer of gold to prevent charging before the observation by SEM.

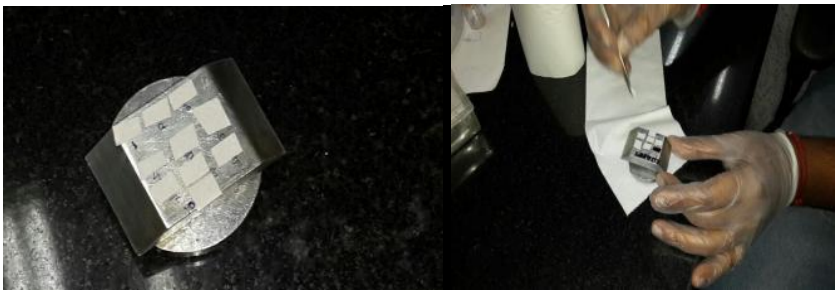

Sample preparation before SEM testing [2]

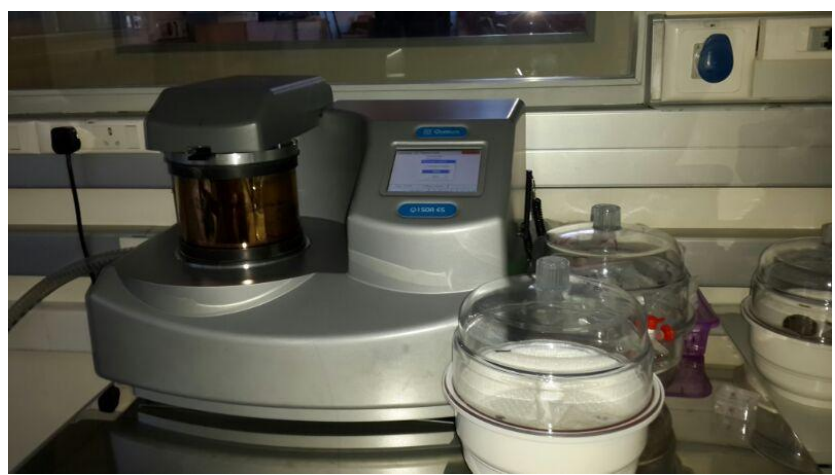

Gold coating after sample preparation before SEM testing[2]

Ultra high resolution scanning electron imaging coupled with material spectroscopy tools

The ULTRA 55 represents the latest development in GEMINI technology. Based on the SUPRA 55, the ULTRA 55 now comprises a fully integrated Energy and angle selective Backscattered electron (EsB) detector. The ULTRA 55 offers ultra high resolution for both SE to image surface information 
and BSE to present compositional information. The new EsB detector features an integrated filtering grid to enhance image quality and requires no additional adjustments. The EsB detector is less sensitive for edge contrast and charging effects which enables precise imaging and measurement of boundaries, particles, and features. Combined with the large multi-port analytical chamber, the fully motorised 5-axes motorised eucentric stage and the GEMINI high current mode the ULTRA 55 also offers superb analytical capabilities.

\subsubsection{Fracture Analysis}

Radiographic Testing were examined using Iridium-192 diameter $2.7 * 1.2 \mathrm{~mm}$, Strength $30 \mathrm{Ci}$ Gamma Ray machine

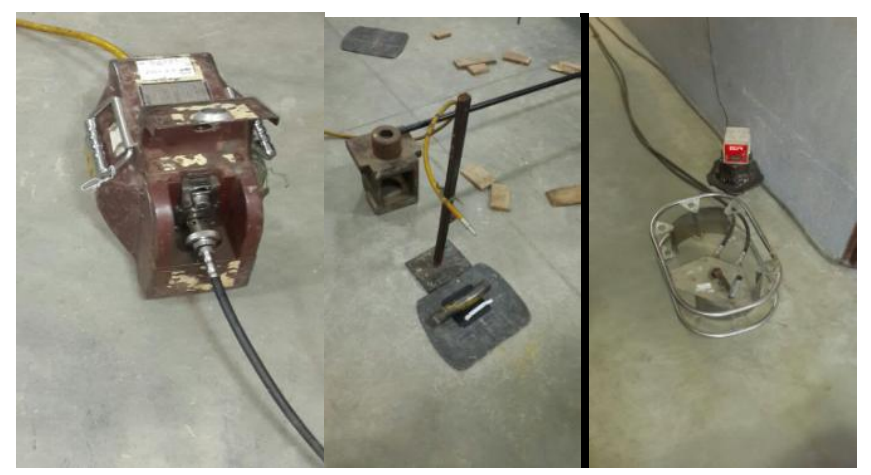

View of a Gamma Ray machine [3]

\subsubsection{Energy-Dispersive X-ray Spectroscopy (EDX)}

\section{Analysis}

EDX is an analytical technique used for the elemental analysis or chemical characterization of a sample. It relies on an interaction of some source of X-ray excitation and a sample. Its characterization capabilities are due in large part to the fundamental principle that each element has a unique atomic structure allowing unique set of peaks on its X-ray spectrum Another way to use SEM/EDX is to make a quantitative chemical analysis of materials.

\subsubsection{Ton Cyclic Loading Machine}

Hydraulic press for testing load comprising Press frame; hydraulic cylinder (dia320Xdia $250 X 250 \mathrm{~mm}$ stroke). Hydraulic power pack 100 it with electric motor $5 \mathrm{hp} \mathrm{X}$ 1440rpm,electrical control panel operating with PLC SCADA software, strain gauge SI $-30 \&$ strain indicator. To conduct the compression tests on all the specimens.

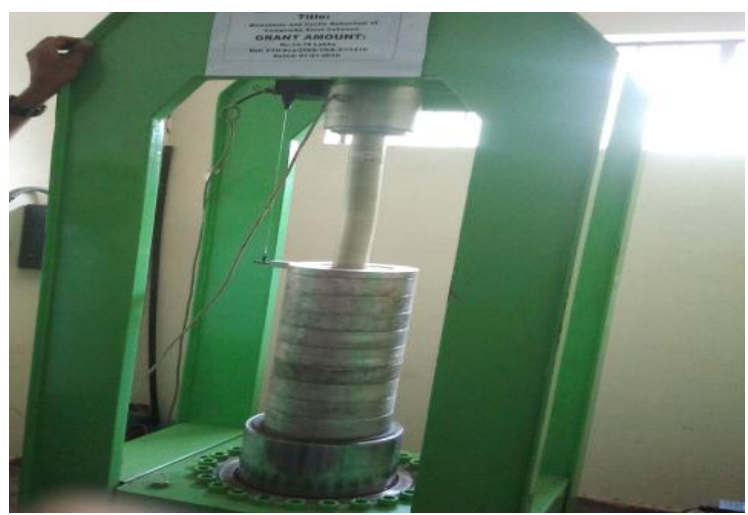

Concrete filled steel tube subjected to monotonic loading [4]
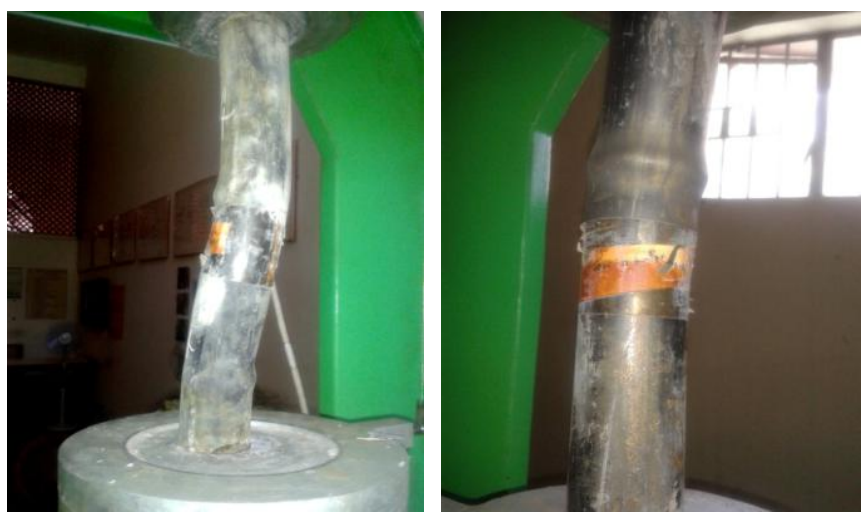

Composite steel tube under testing [4]

\section{RESULTS \& DISCUSSIONS}

\subsection{Scanning electron microscopy (SEM)}

\section{Sample1- 1:2:3(Cement: HNC: Sand)}
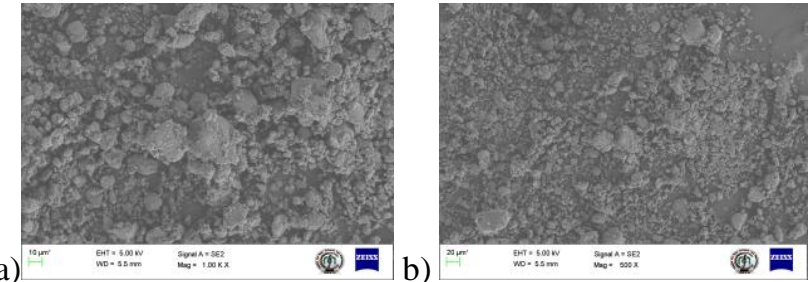

a)

b)
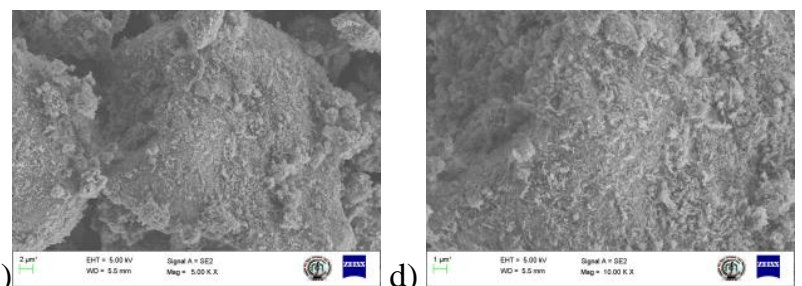

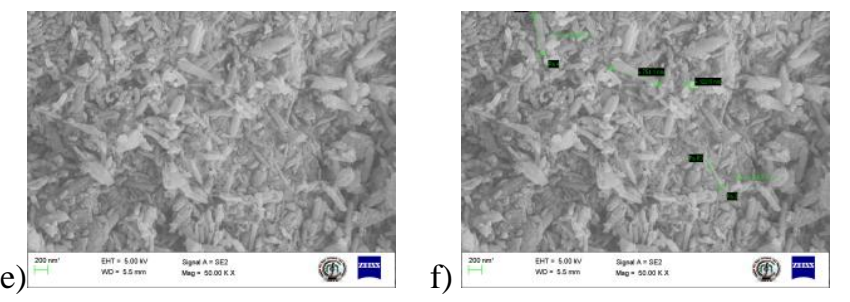

Fig1. SEM Images of fracture surface morphology from low to high magnification (a-f)

Sample1- Energy-dispersive X-ray spectroscopy (EDX) Analysis
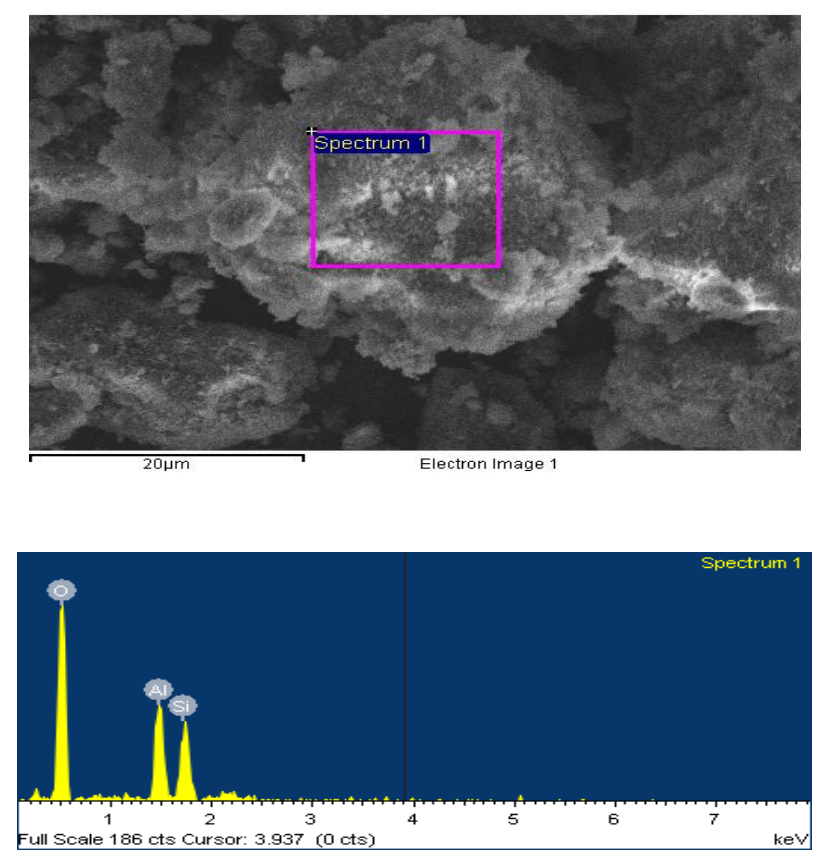

Sample2- 1:1.5:3 (Cement: HNC: Sand)
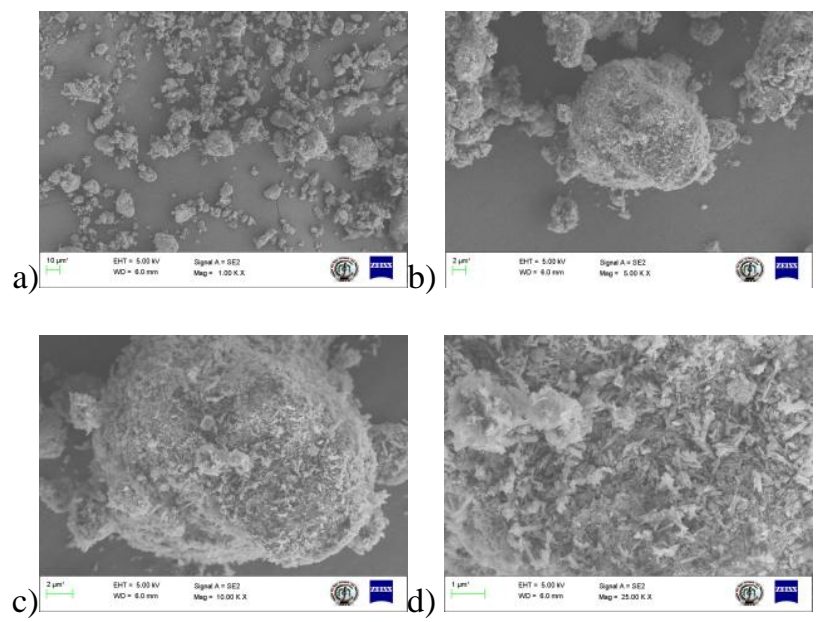
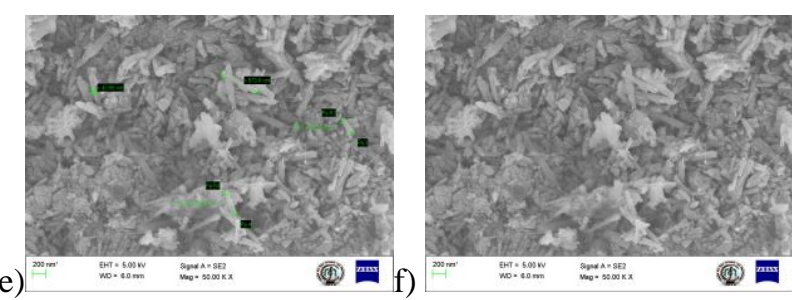

Fig2. SEM Images of fracture surface morphology from low to high magnification (a-f)

Sample2- Energy-dispersive X-ray spectroscopy (EDX) Analysis
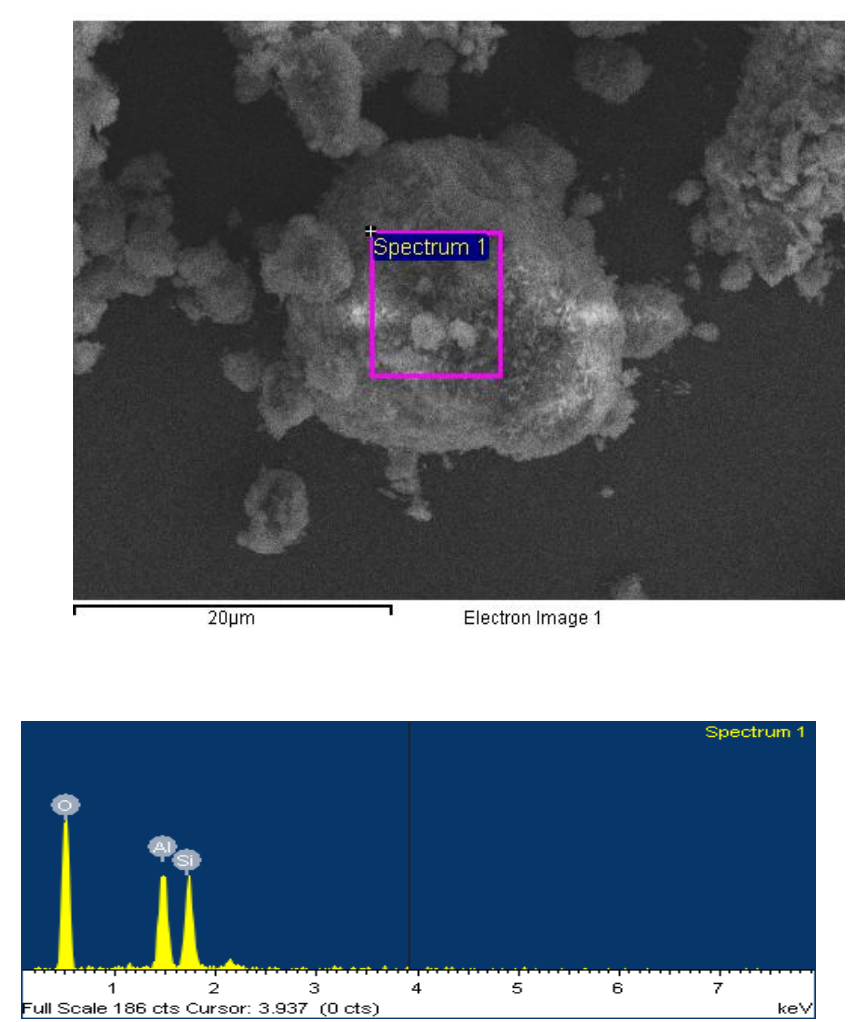

\section{Sample3- 1:2 (Cement: HNC)}

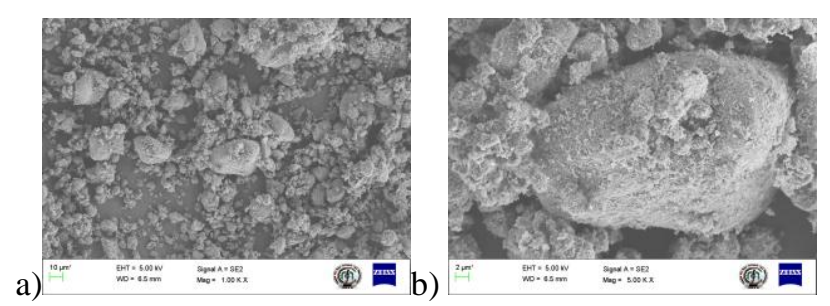


c)
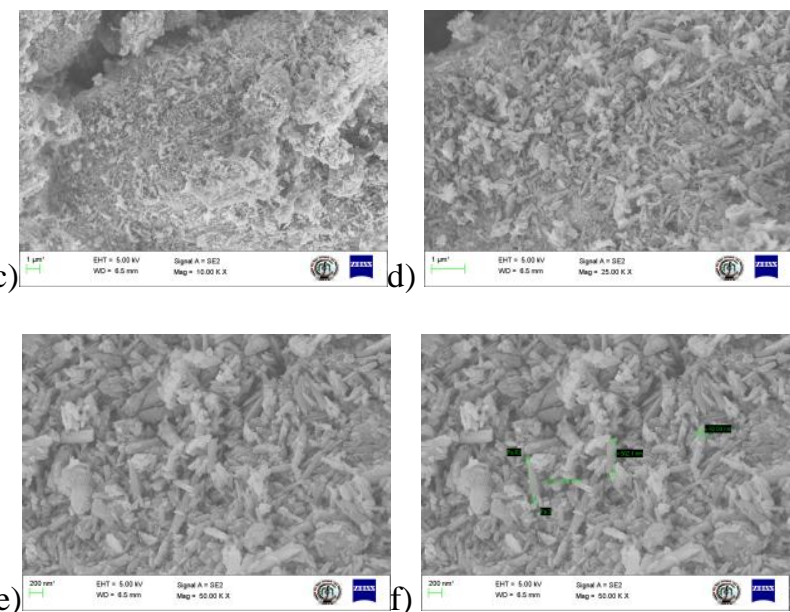

Fig3. SEM Images of fracture surface morphology from low to high magnification (a-f)

\section{Sample3- Energy-dispersive X-ray spectroscopy} (EDX) Analysis
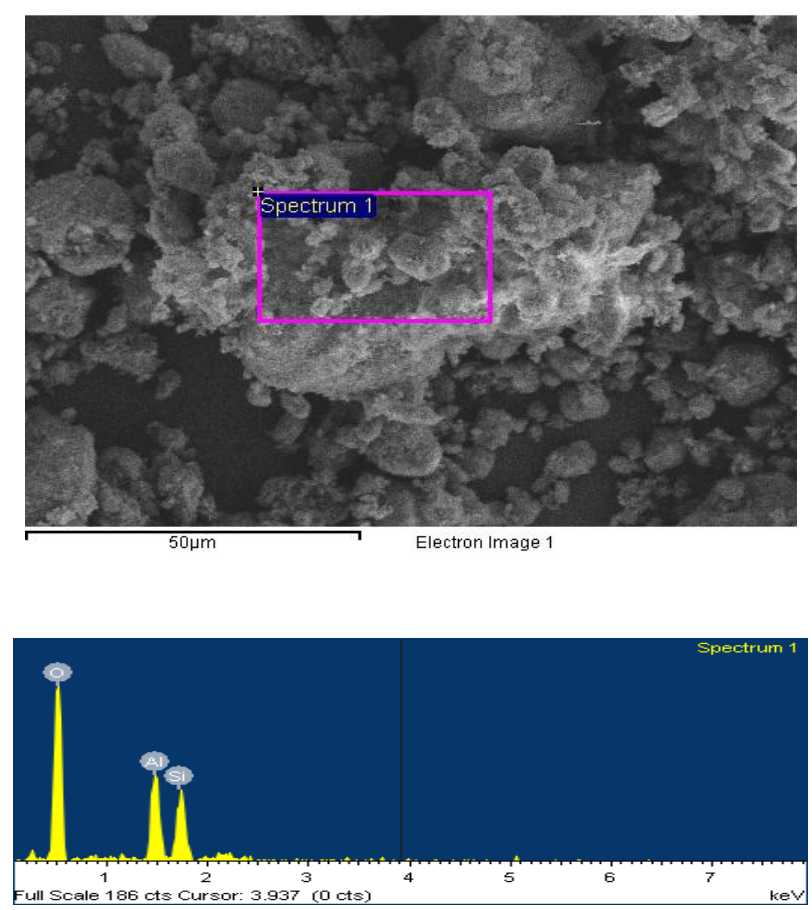

Sample4- 2:3 (HNC: Sand)

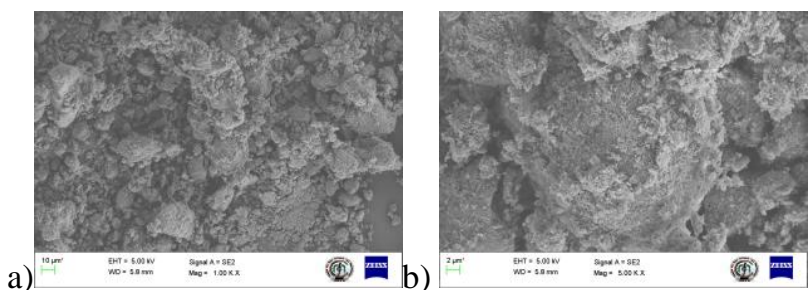

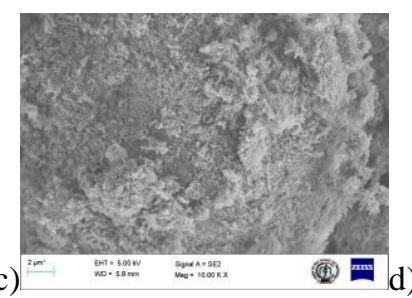
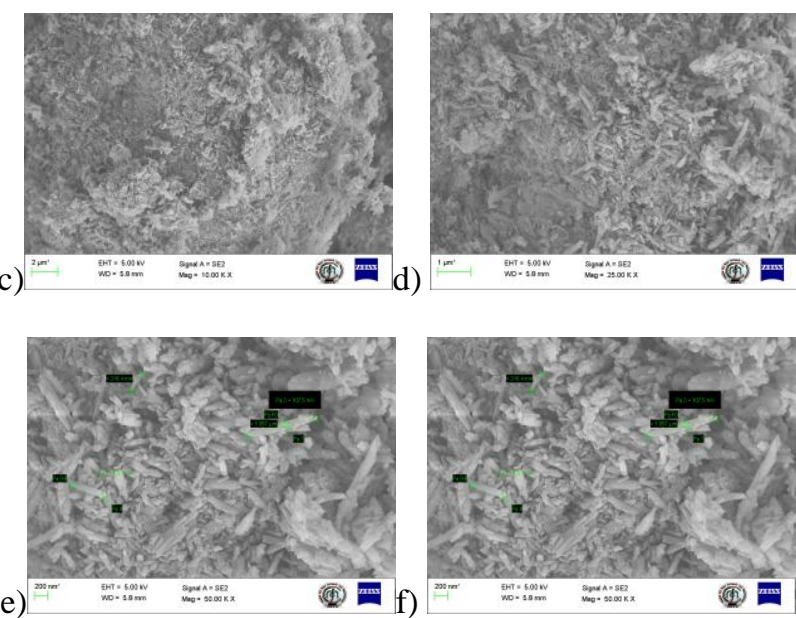

Fig4. SEM Images of fracture surface morphology from low to high magnification (a-f)

Sample4- Energy-dispersive X-ray spectroscopy (EDX) Analysis
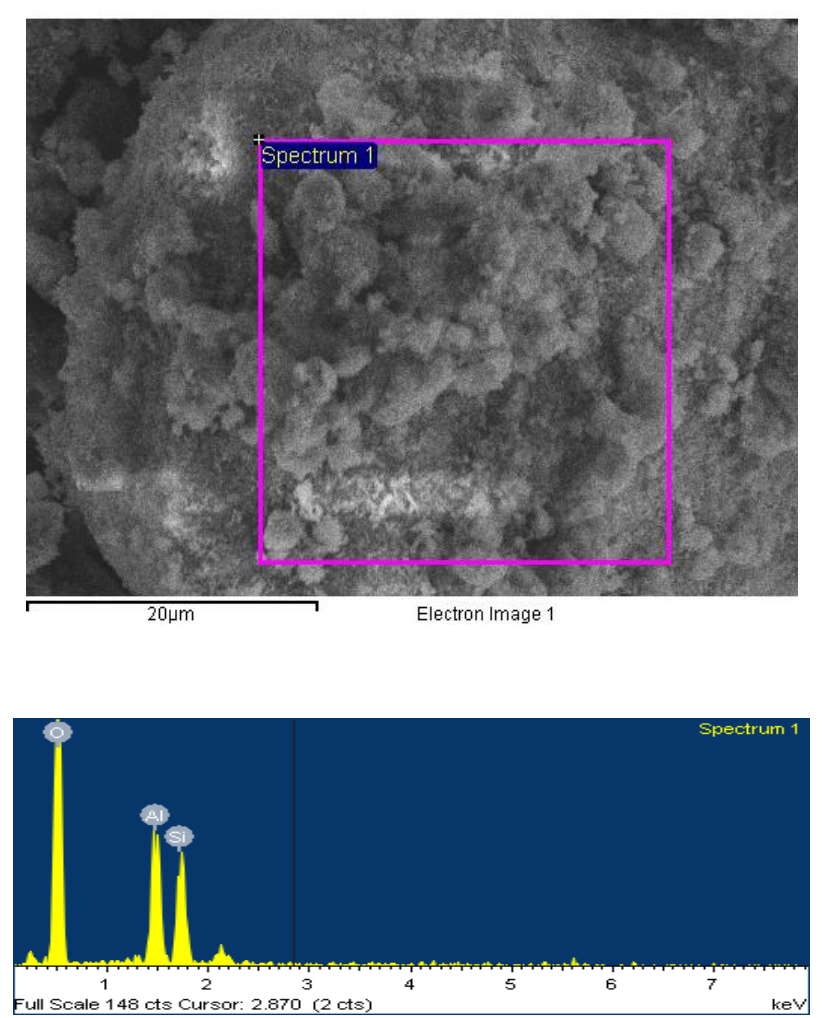

Volume: 03 Special Issue: 06 | May-2014 | RRDCE - 2014, Available @ http://www.ijret.org 


\section{Sample5- 1:1.5 (Cement: HNC)}

a)
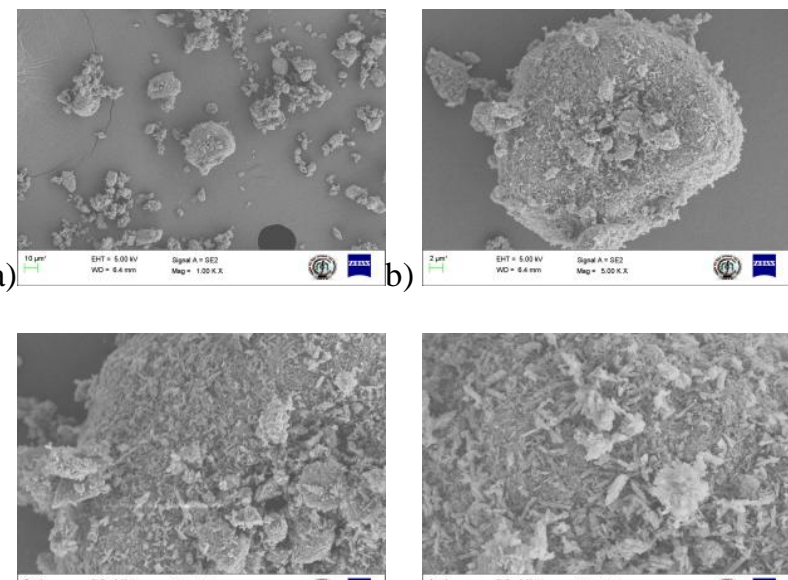

c)
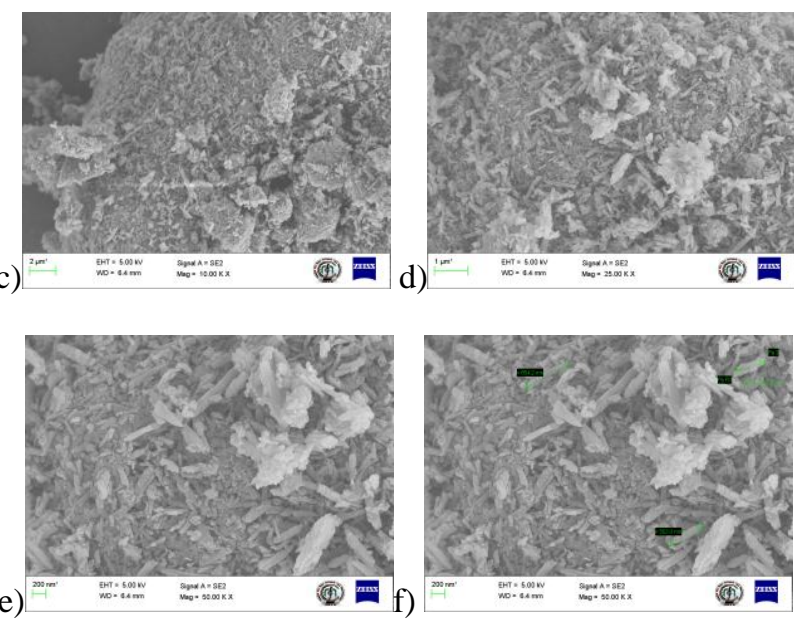

Fig5. SEM Images of fracture surface morphology from low to high magnification (a-f)

Sample5- Energy-dispersive X-ray spectroscopy (EDX) Analysis
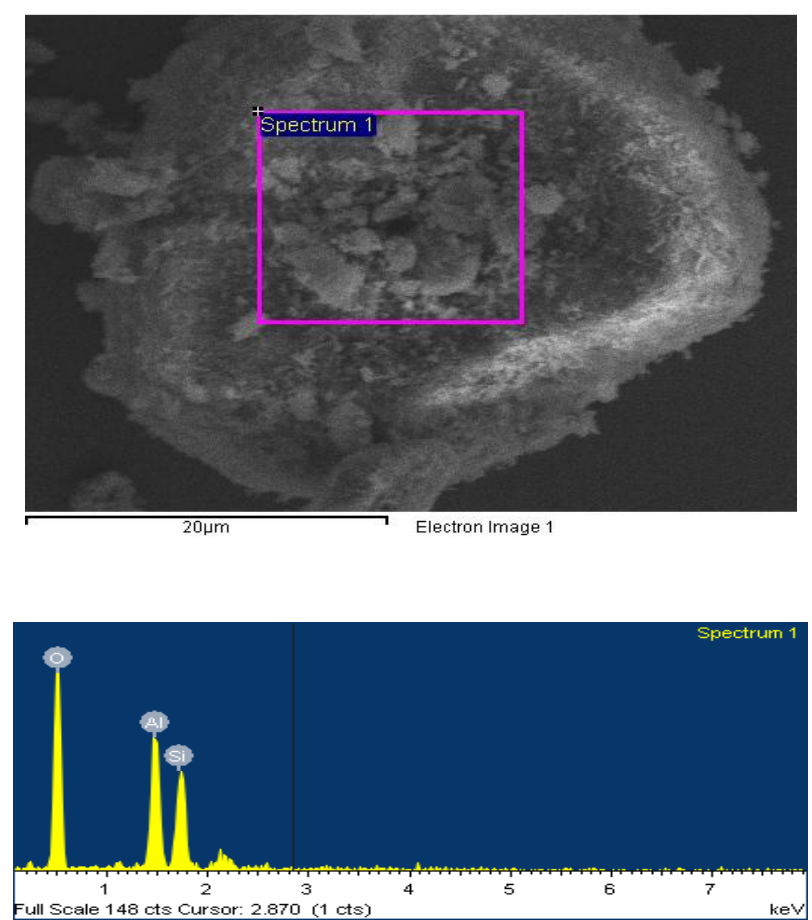

\section{Sample6- 1.5:3 (HNC: Sand)}

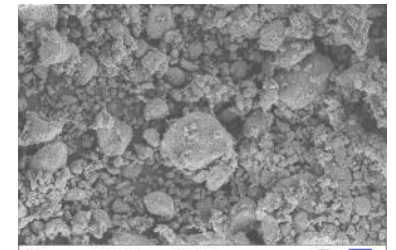

a)

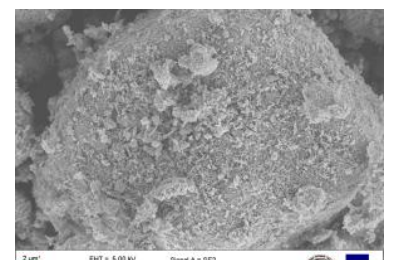

(19) b)

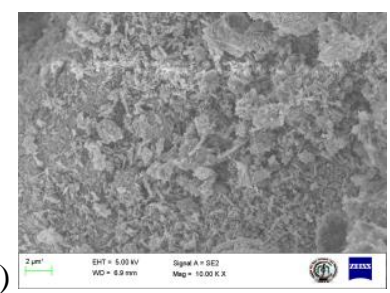

c)
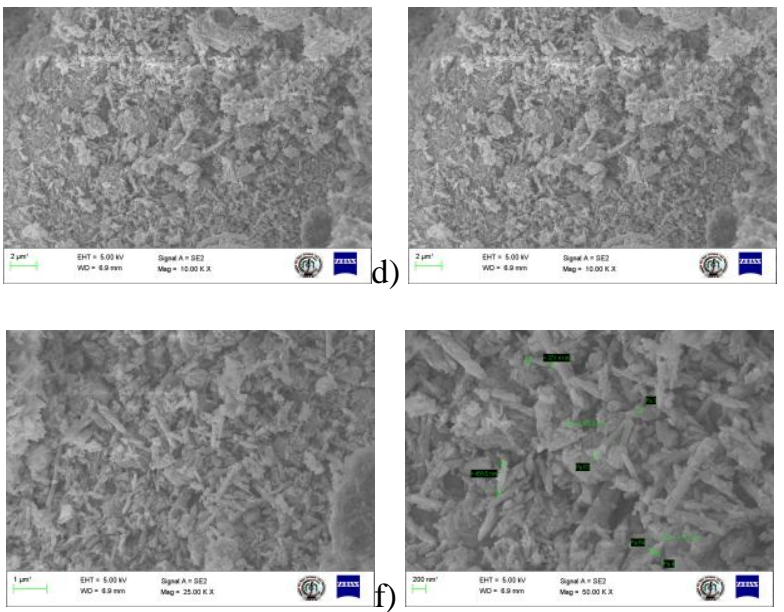

e)

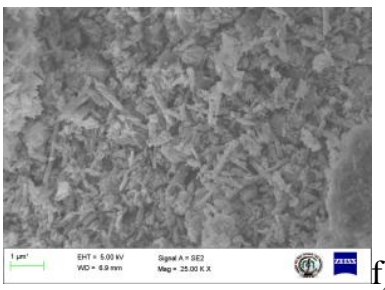

Fig6. SEM Images of fracture surface morphology from low to high magnification (a-f)

Sample6- Energy-dispersive X-ray spectroscopy (EDX) Analysis
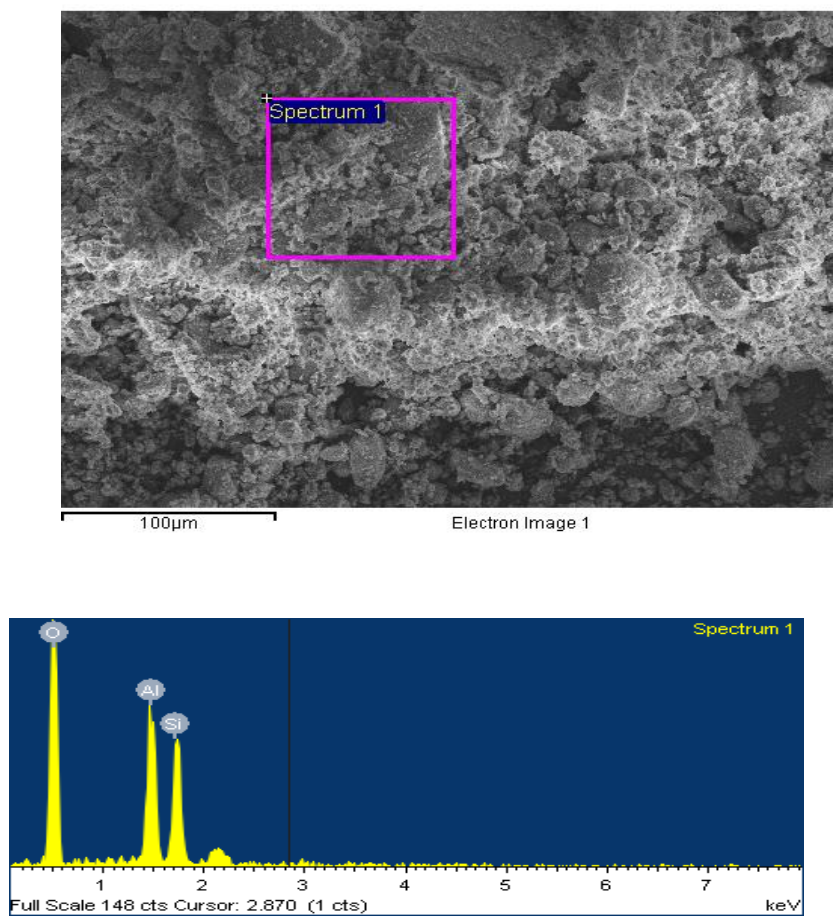


\section{Sample7- Cement}

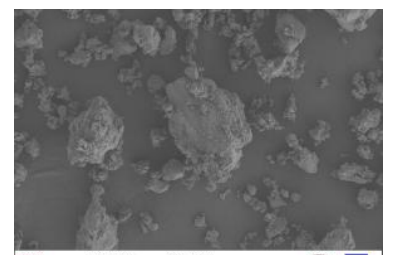

a)
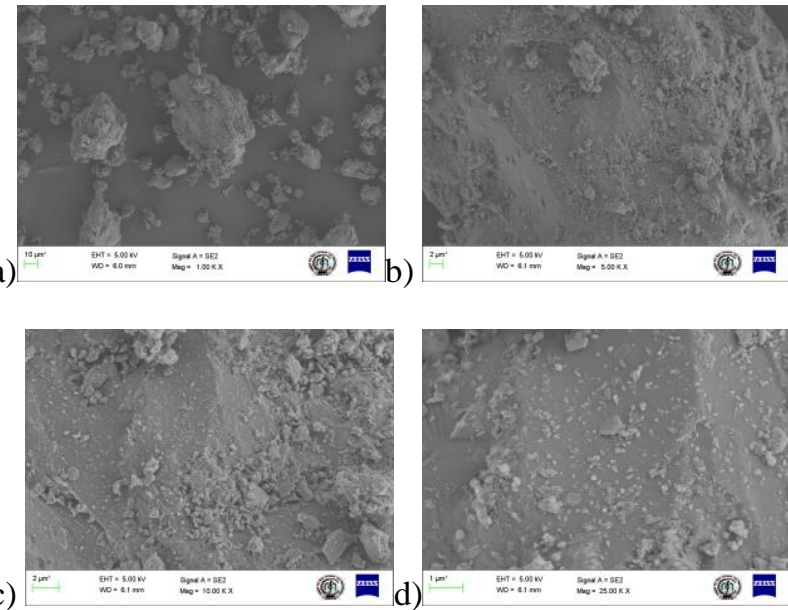

c)
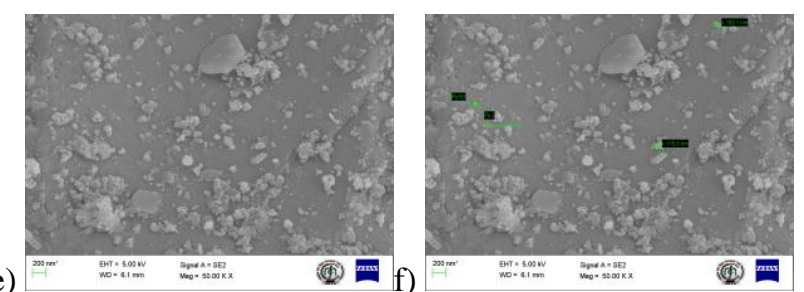

Fig7. SEM Images of fracture surface morphology from low to high magnification (a-f)

Sample7- Energy-dispersive X-ray spectroscopy (EDX) Analysis
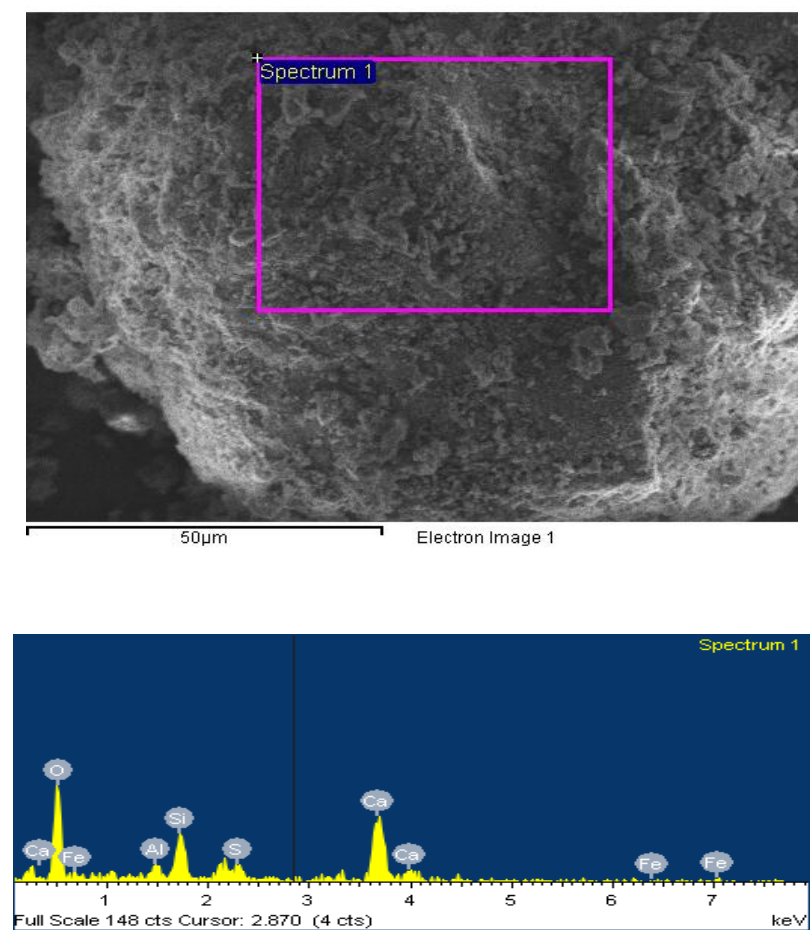

\section{Sample8- HNC's}

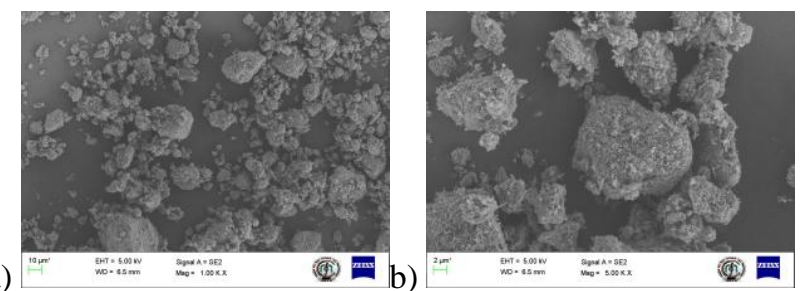

c)
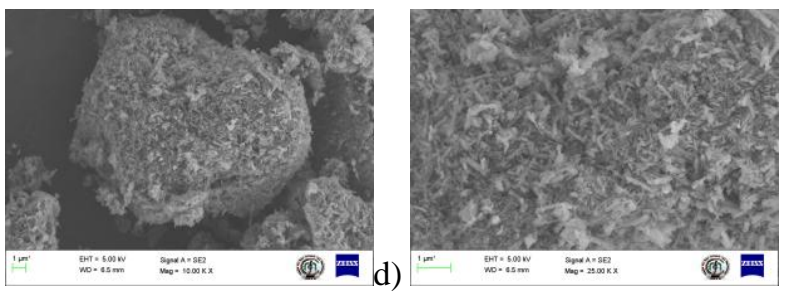

e)
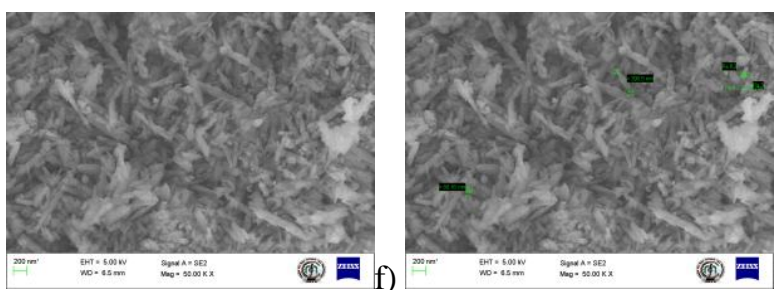

Fig8. SEM Images of fracture surface morphology from low to high magnification (a-f)

Sample8- Energy-dispersive X-ray spectroscopy (EDX) Analysis
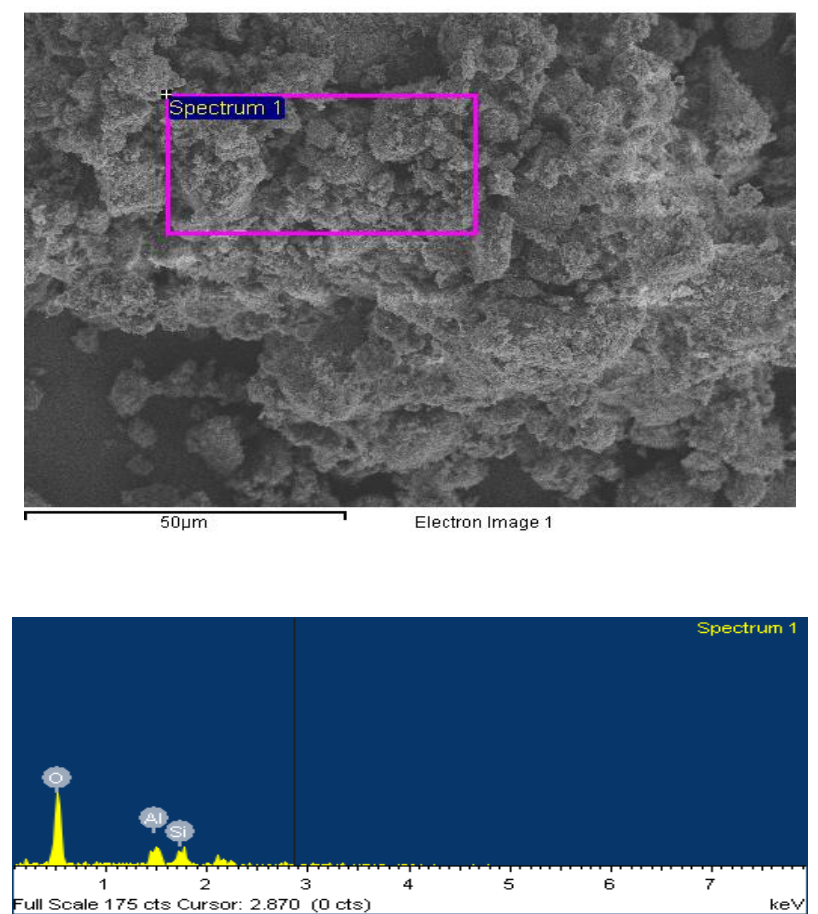


\section{Sample9- Sand}

a)
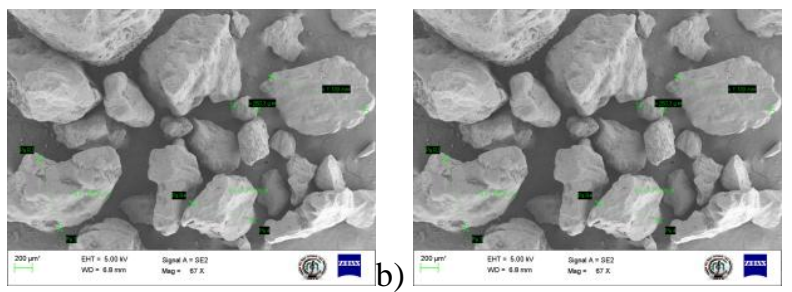

c)
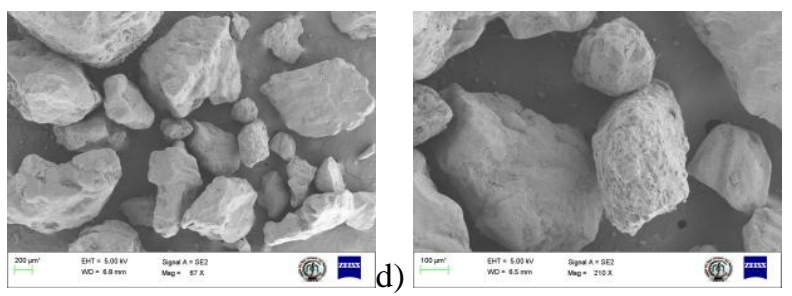

Fig9. SEM Images of fracture surface morphology from low to high magnification (a-f)

Sample9- Energy-dispersive X-ray spectroscopy (EDX) Analysis
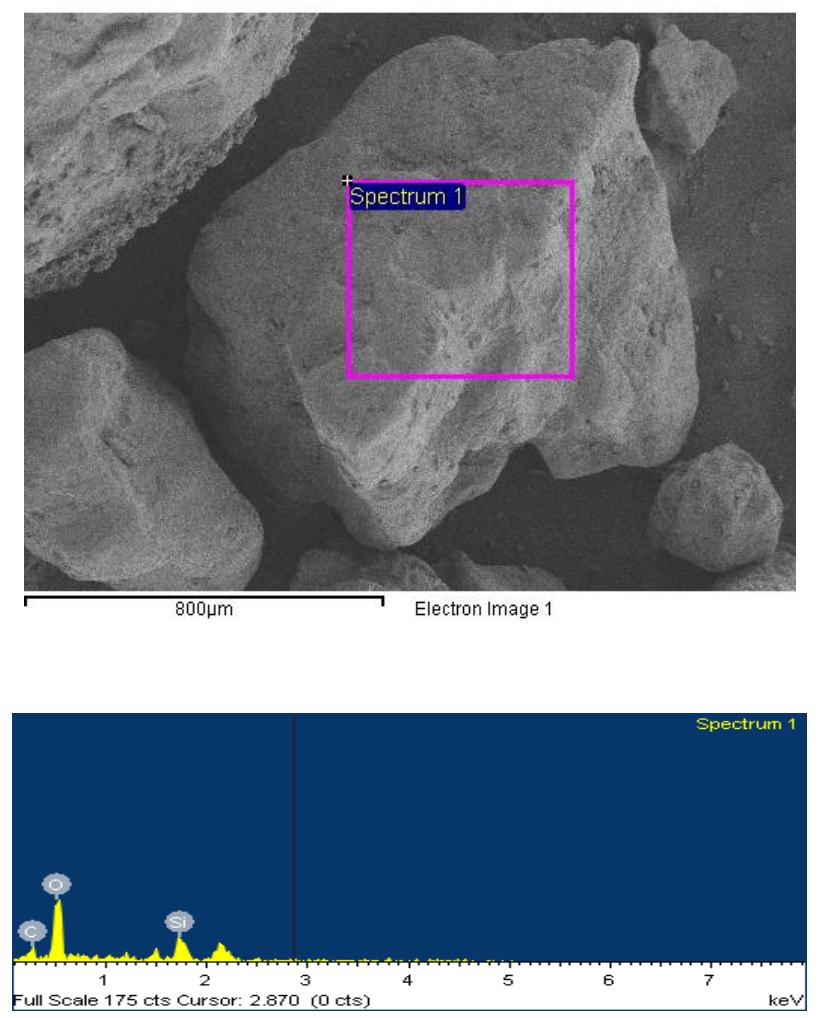

\section{Sample10- After compression testing}
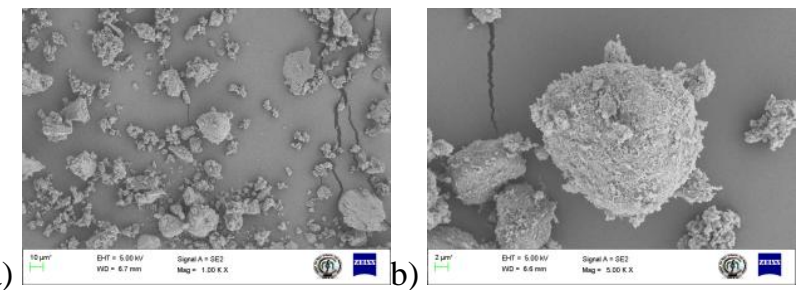

c)
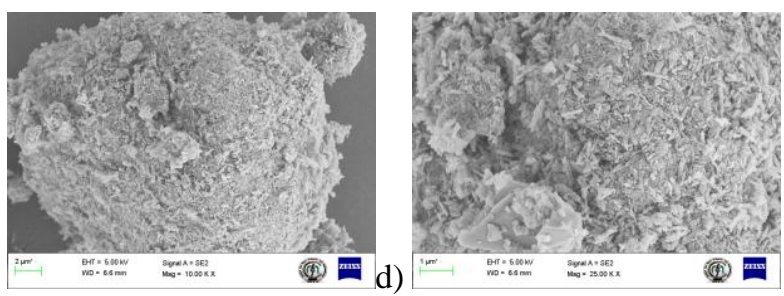

e)

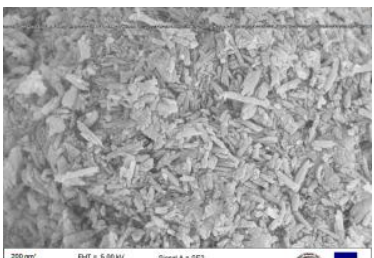

(12) $\mathrm{fm}$

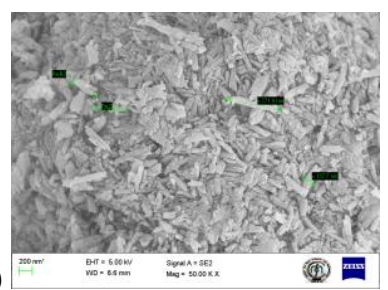

Fig10. SEM Images of fracture surface morphology from low to high magnification (a-f)

Sample10- Energy-dispersive X-ray spectroscopy (EDX) Analysis
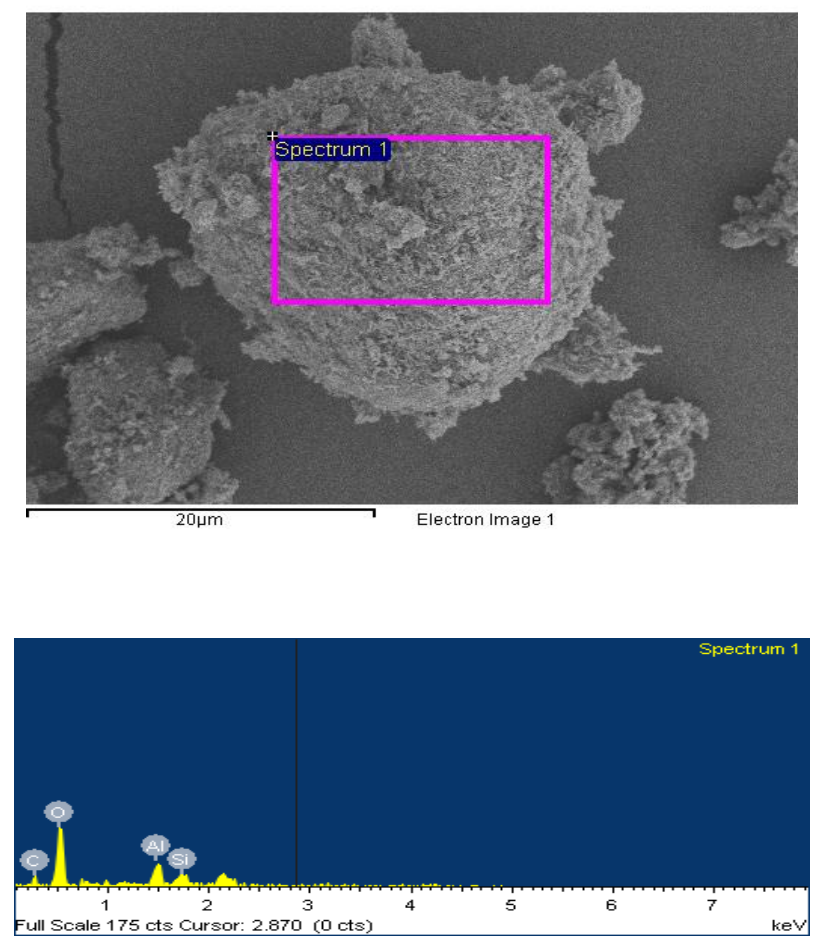


\subsection{Fracture Analysis}

Radiographic Testing were examined for the samples

1) Length $300 \mathrm{~mm}, \mathrm{c} / \mathrm{s} 3 * 3 \mathrm{~mm}$-stainless steel

2) Length $300 \mathrm{~mm}$, diameter $23 \mathrm{~mm}$-middle steel

3) Length $280 \mathrm{~mm}$, diameter $22 \mathrm{~mm}$ - middle steel

4) Length $30 \mathrm{~mm}$, diameter $30 \mathrm{~mm}$-middle steel

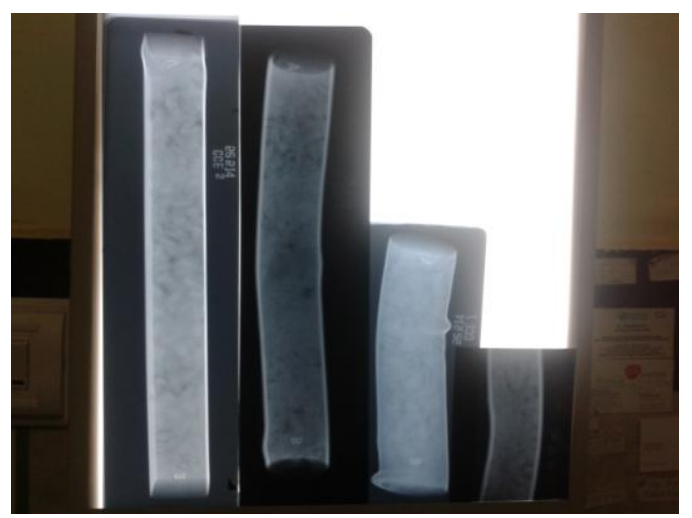

Fig 11 radiographic film

When the Tube was monotonically loaded it was observed that crack patters as shown in the fig1 \& were obtained from the radiographic testing and further work is being carried out by the author for modeling the future using facture analysis approach and for further developing the mathematical modeling for facture.

\subsection{Experimental Results}

Length $300 \mathrm{~mm}$, diameter $22 \mathrm{~mm}$, thickness $5 \mathrm{~mm} \& \mathrm{M} 20$ $(1: 2: 3)$ concrete.

\begin{tabular}{|l|l|l|}
\hline \multicolumn{2}{|l|}{ Ultimate load $\left(\mathbf{P}_{\text {ult }}\right)$ in KN } & \\
\hline $\begin{array}{l}\text { Without } \\
\text { HNC's }\end{array}$ & $\begin{array}{l}\text { With } \\
\text { HNC's }\end{array}$ & $\begin{array}{l}\text { HNC's } \\
\text { in \% }\end{array}$ \\
\hline 84 & $\mathbf{8 5 . 6 8}$ & $\mathbf{0 . 5}$ \\
\hline $\mathbf{8 6 . 1 0}$ & $\mathbf{8 8 . 2 5}$ & $\mathbf{1 . 0}$ \\
\hline $\mathbf{8 6 . 5 2}$ & $\mathbf{8 9 . 1 1}$ & $\mathbf{1 . 5}$ \\
\hline $\mathbf{8 7 . 3 6}$ & $\mathbf{8 2 . 3 2}$ & $\mathbf{2 . 0}$ \\
\hline
\end{tabular}

Fig 12- Result Table

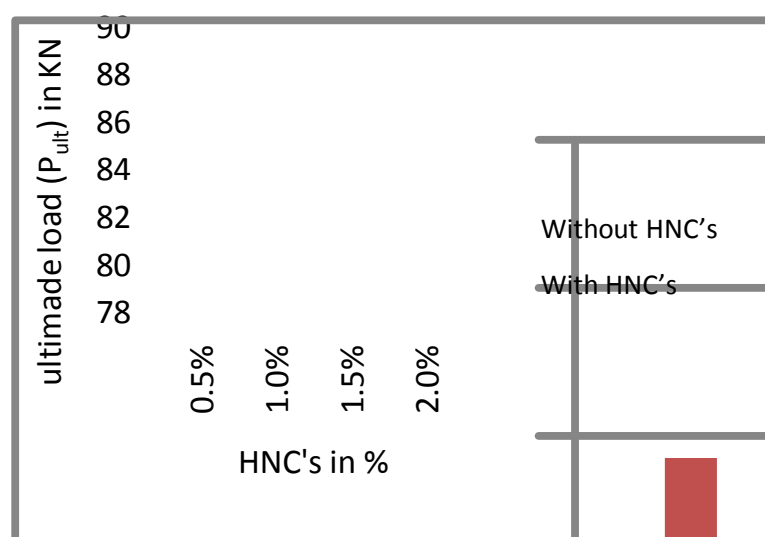

Fig 13- Ultimate load $\left(\mathrm{P}_{\text {ult }}\right)$ vs. HNC's graph

\section{CONCLUSIONS}

Physical and chemical properties of the HNC's tested were founded to be very positive for civil engineering applications. Especially it has light weight and is in the powder form which can mix well with the cement \& sand. Tests are being conducted for the compressive strength of HNC's. When mixed with only cement, only sand \& all the three. SEM \& EDX analysis are show's that HNC's can lead to homogenous mixture which in turns enhances load caring capacity of composite steel column.

As shown in the fig 2 as percent of HNC's increase load also increase observed and ultimate load $\left(\mathrm{P}_{\mathrm{ult}}\right)$ is increased but reached optimum and started deceasing between 1.5 to $2.0 \%$.

\section{ACKNOWLEDGEMENTS}

Authors are highly indebted to Dr Girish Kunte, Micro \& Nano Characterization Facility (MNCF) Center for Nano Science and Engineering (CENSE) IISc, Bangalore. Dr. Sudha Joseph, Dept of Material Engineering, IISc, Bangalore. Mr. Gadhadar, NoPo Nanotechnologies India Pvt Ltd, Bangalore. Sigma Aldrich ${ }^{\circledR}-N e w$ Zealand. Pallakki NDT Excellence Center, Peenya, Bangalore.

\section{REFERENCES}

[1]. Sigma Aldrich $®$ Bommasandra, Bangalore.

[2]. Micro \& Nano Characterization Facility (MNCF) Center for Nano Science and Engineering (CENSE) IISc, Bangalore

[3]. Pallakki NDT Excellence Center, Peenya, Bangalore

[4]. R\&D Lab, Dept of Civil Engineering, GCE, Ramanagaram.

[5]. Alamri H, Low IM. Microstructural, mechanical, and thermal characteristics of recycled cellulose .ber-halloysiteepoxy hybrid nanocomposites. Polym Compos 2012;33(4):589-600. 
[6]. Churchman GJ, Davy TJ, Aylmore LAG, Gilkes RJ, Self PG. Characteristics of .nepores in some halloysites. Clay Miner 1995;30:89-98.

[7]. Joussein E, Petit S, Churchman J, Theng B, Right D, Delvaux B. Halloysite clay minerals a review. Clay Miner 2005;40:383-426.

[8]. Smith ME, Neal G, Trigg MB, Drennan J. Structural characterization of the thermal transformation of halloysite by solid-state NMR. Appl Magn Reson 1993;4:157-70.Cer

[9]. Fix, D., Andreeva, D.V., Lvov, Y.M., Shchukin, D.G., Möhwald, H., 2009.

[10]. Application of inhibitor-loaded halloysite nanotubes in active anti-corrosive coatings. Advanced

[11]. Functional Materials 19 (11), 1720-1727.2006. Layerby-layer assembled nanocontainers for self-healing corrosion protection. Advanced Materials 18 (13), 1672-1678.

[12] Prashantha K, Lacrampe MF, Krawczak P. Processing and characterisation of halloysite nanotubes filled polypropylene nanocomposites based on a master batch route: effect of halloysites treatment on structural and mechanical properties. Express Polym Lett 2011;5(4):295-307.

[13]. Handge UA, Hedicke-Höchstötter K, Altstädt V. Composites of polyamide- 6 and silicate nanotubes of the mineral halloysite: in.uence of molecular weight on thermal, mechanical and rheological properties. Polymer 2010;51(12):2690-9.

[14]. Lin Y, Ng KM, Chan C-M, Sun G, Wud J. High-impact polystyrene/halloysite nanocomposites prepared by emulsion polymerization using sodium dodecyl sulfate as surfactant. J Colloid Interface Sci 2011;358:423-9.

[15]. Yuan Q, Misra RDK. Polymer nanocomposites: current understanding and issues. Mater Sci Technol 2006;22:742-55.

[16]. Friedrich K, Fakirov S, Zhang Z. Polymer composites: from nano-to-macro-scale. (USA): Springer Science \& Business Media, Inc.; 2005.

[17]. Deng S, Zhang J, Ye L. Halloysite-epoxy nanocomposites with improved particle dispersion through ball mill homogenisation and chemical treatments. Compos Sci Technol 2009;69:2497-505.

[18]. Morote-Martinez V, Pascual-Sanchez V, MartinMartinez JM. Improvement in mechanical and structural integrity of natural stone by applying unsaturated polyester resin-nanosilica hybrid thin coating. Eur Polym J 2008;44:3146-55.

\section{BIOGRAPHIES}

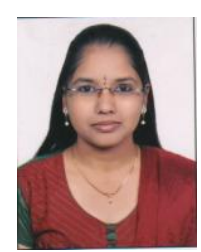

Graduated in the year 2011 from VTU, Belgaum Presently perusing Master of Technology in Structural Engineering at Ghousia College of Engineering, Ramanagaram Also working on this topic for the dissertation under the guidance of Dr. N S

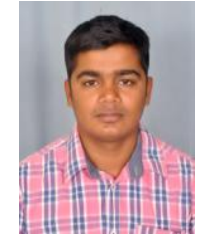

Graduated in the year 2012 from VTU, Belgaum. Presently perusing Master of Technology in Structural Engineering at Ghousia College of Engineering, Ramanagaram Also working on this topic for the dissertation under the guidance of Dr. N S Kumar

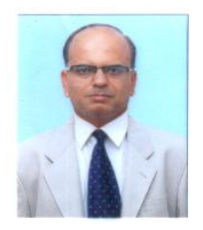

Involved in the Research field related to behavior of Composite Steel Column since a decade Presently guiding four Ph.D Scholars, including one M.Sc Engineering (Research under VTU, Belgaum) Has more than 25 years of teaching experience \& 6 years of Research experience at Ghousia College of Engineering, Ramanagaram.

Kumar 